\title{
Seasonal patterns of outdoor PM infiltration into indoor environments: review and meta-analysis of available studies from different climatological zones in Europe
}

\author{
Otto Hänninen • Gerard Hoek • Sandra Mallone • Elisabetta Chellini • \\ Klea Katsouyanni • Claudio Gariazzo • Giorgio Cattani - Achille Marconi • \\ Peter Molnár • Tom Bellander • Matti Jantunen
}

Received: 22 December 2009 / Accepted: 26 May 2010 /Published online: 23 June 2010

(C) Springer Science+Business Media B.V. 2010

\begin{abstract}
Epidemiologists have observed higher risks for exposure to ambient particulate matter (PM) in the summer than in other seasons. This increased risk may be partly due to seasonal behaviour and higher exposures to indoor PM in the summer in relation to outdoor pollutant levels during winter when windows are kept closed and less time is spent outdoors. In this report, we analyse data from six European studies, based on three different methods of estimating outdoor to indoor infiltration factors, with the aim of characterizing the geographical and seasonal patterns of PM infiltration. The highest infiltration levels were observed for the summer in both a European combined dataset consisting of 382 observations of the average $\mathrm{PM}_{2.5}$ infiltration factor for 1 day to 2 weeks in regional data sets for Northern, Central and Southern Europe as well as for all ten cities individually. Th lowest values were observed for the winter,
\end{abstract}

O. Hänninen $(\varangle) \cdot$ M. Jantunen

Environmental Health,

National Institute for Health and Welfare (THL),

POB 95, 70701 Kuopio, Finland

e-mail: otto.hanninen@thl.fi

URL: www.thl.fi/en

G. Hoek

Institute for Risk Assessment Sciences (IRAS),

Utrecht University,

Utrecht, Netherlands

S. Mallone $\cdot$ E. Chellini

Cancer Prevention and Research Institute,

Florence, Italy

K. Katsouyanni

Medical School, University of Athens,

Athens, Greece with spring and autumn displaying intermediate values. In all datasets and cities, the variability between residences and days within each season was much higher than the seasonal trend. $\mathrm{PM}_{10}$ data were available from two studies, revealing that the $\mathrm{PM}_{10}$ infiltration factors ranged from 70 to $92 \%$ of the corresponding $\mathrm{PM}_{2.5}$ values. Some differences between the studies may be associated with the study designs and applied methods of determining the infiltration factor. The ratio of summer to winter $\mathrm{PM}_{2.5}$ infiltration ranged from 1.3 in Rome to 2.3 in Helsinki, and the corresponding regional ratio ranged from 1.5 in Central Europe to 1.8 in Northern and Southern Europe. It is suggested that similar differences can be expected in epidemiological concentration-response relationships due to the modification in seasonal exposure associated with buildings and time spent indoors.

C. Gariazzo

ISPESL-DIPIA,

Monteporzio Catone (RM), Italy

G. Cattani

Institute for Environmental Protection and Research,

Rome, Italy

A. Marconi

Istituto Superiore di Sanità,

Rome, Italy

P. Molnár

University of Gothenburg,

Gothenburg, Sweden

T. Bellander

Institute of Environmental Medicine, Karolinska Institutet,

Stockholm, Sweden 
Keywords Ambient particulate matter (PM) - Infiltration . Ventilation · Seasonal effects · Exposure misclassification

\section{Introduction}

Risk assessments based on epidemiological concentrationresponse $(\mathrm{C}-\mathrm{R})$ functions have shown that larger adverse health effects are associated with exposures to particulate matter (PM) than any other environmental contaminant in the developed world (e.g. de Hollander et al. 1999; WHO 2003). In Europe (EU-25) ambient air fine PM $\left(\mathrm{PM}_{2.5}\right)$ has been estimated to cause approximately 350,000 premature deaths annually (Watkiss et al. 2005). The epidemiological studies are almost exclusively based on fixed-site outdoor measurements as a descriptor of the population exposures. However, a strong body of scientific literature has shown that exposures are modified by time spent indoors and population mobility (e.g. Koistinen et al. 2001) and, therefore, the relationship of personal exposures to outdoor concentrations is a significant factor in the interpretation of the epidemiological risk coefficients even when the existence of indoor sources is ignored and focus is placed on PM of ambient origin.

The 2003 heat waves in Europe and associated excess mortality peaks intensified research on the interactions of weather, especially temperature, and PM air pollution (e.g. Bell et al. 2008; Nawrot et al. 2007; Samoli et al. 2005). In the large European time-series study APHEA, Samoli et al (2005) observed higher relationships for $\mathrm{PM}_{10}$ above the 75th percentile of daily temperatures, representing mainly the warm season, than below the 25th percentile (cold season). The difference was especially profound for black smoke present dominantly in the sub-micron particle size fraction. Nawrot et al. (2007) also reported the strongest and most linear association between $\mathrm{PM}_{10}$ and mortality for the summer season in Flanders, Belgium. In Italy. Stafoggia et al. (2008) observed a $2.54 \%$ increase in mortality per $10 \mu \mathrm{g} \mathrm{m}^{-3} \mathrm{PM}_{10}$ during the summer $(95 \%$ confidence interval (CI) 1.31-3.78) compared with $0.20 \%$ (95\% CI -0.08 to 0.49$)$ in the winter. It has been suggested that these findings, rather than indicating a difference in the toxicity of summer and winter particles, or enhancement of the PM toxicity by temperature and associated factors, such as ozone, result from exposure to the ambient concentration during the cold season being more heterogeneous due to the differences in indoor and outdoor concentrations. Therefore, the observed $\mathrm{C}-\mathrm{R}$ relationship is biased towards zero (Hänninen and Jantunen 2007).

In contrast, researchers conducting a large U.S. study encompassing 202 counties observed the highest association with $\mathrm{PM}_{2.5}$ and hospital admissions due to cardiovascular diseases in the winter, with a $1.49 \%(95 \%$
CI 1.09-1.89) increase in hospitalizations per $10 \mu \mathrm{g} \mathrm{m}^{-3}$ increase in same-day $\mathrm{PM}_{2.5}$ (Bell et al. 2008). This observation may be explained by the general use of air conditioning in U.S. homes, which results in the detachment of indoor air from outdoor PM, especially during the summer (Janssen et al. 2002). In contrast, in Europe, buildings are mostly cooled by keeping the windows open, and the opposite effect emerges.

Complex relationships exist between the variables, and it has also been suggested that PM could modify the effects of temperature. Ren et al. (2006) reported that ambient $\mathrm{PM}_{10}$ modified the effects of air temperature on respiratory and cardiovascular hospital admissions, all non-external-cause mortality and cardiovascular mortality with different lags. It has even been suggested that the acute effects of PM on mortality in the National Morbidity, Mortality, and Air Pollution Study (NMMAPS) result from inadequate control for weather and season (Welty and Zeger 2005). To improve our understanding of whether summer particles are less or more harmful than winter particles, whether PM health effects are modified by temperature or whether even the observed association between PM and health actually is caused by inadequate control for season and weather, it is important to understand the potential seasonal differences in the relationship between population exposure levels and outdoor concentrations.

Two parameters of particular interest have been proposed as tools for studying the population exposure to ambient concentration relationship. Wilson et al. (2000) and Wilson and Brauer (2006) defined the population exposure levels to outdoor concentrations ratio for ambient particles as the attenuation factor $(\alpha)$. In the study reported here, we focus on one of the main determinants of the attenuation factor, namely infiltration. Infiltration factor $\left(\mathrm{F}_{\text {inf }}\right)$ is defined as the equilibrium fraction of ambient particles $\mathrm{C}_{\mathrm{a}}$ ) that penetrate indoors and remain suspended $\mathrm{C}_{\mathrm{ai}}$ ). When no indoor sources of particles are present, the infiltration factor can be approximated by the indoor/outdoor ratio. The infiltration factor is affected by air exchange rate $(a)$, penetration efficiency $(P)$ and deposition rate $(k)$ according to Eq. 1 (presented earlier without the term " $F_{\text {inf }}$ " by, for example, Dockery and Spengler 1981; see a concise summary of the concept development in Hänninen et al. 2004a):

$F_{I N F}=\frac{C_{a i}}{C_{a}}=\frac{P a}{a+k}$

Of the variables in the equation, only the ambient concentration is routinely measured. The air exchange rate measurement involves typically marker substances, and penetration efficiency and deposition rate can be observed only indirectly. Therefore, despite the apparent simplicity and importance of infiltration for exposures and the interpretation 
of the epidemiological ambient $\mathrm{C}-\mathrm{R}$ relationships, there is relatively little population-based data available.

The penetration efficiency and deposition rate are to some extent affected by the geometry of the indoor spaces and air intake ducts and leaks, but they are mostly affected by the properties of the aerosol, including particle settling and thermokinetic velocities and volatility. Variability in the PM infiltration between different days in buildings and between buildings is mainly caused by the air exchange rate. In buildings with natural ventilation, the air exchange rate depends on the temperature difference between the indoor and outdoor air, the wind pressure outside the building and whether the occupants keep windows open or closed.

Long et al. (2001) demonstrated the dependency of PM penetration efficiency on both particle size and home characteristics and observed minimum infiltration factors for ultrafine and coarse particles in nine Boston homes. The results agree with those predicted from aerosol physics. The model development with the same dataset was continued by Bennet and Koutrakis (2006) for particle size-dependent infiltration factors with a dynamic model and nighttime data from seven residences. These researchers found a mean infiltration factor of 0.49 for the smallest particle size fraction $(0.02-0.03 \mu \mathrm{m})$ across all homes, increasing up to 0.76 for the 0.2 - to $0.3-\mu \mathrm{m}$ size fraction and then decreasing steadily to 0.32 for the largest monitored particle size fraction $(4-6 \mu \mathrm{m})$. The coefficients of variation between the sampling nights and between the homes were determined and found to be comparable, ranging between 0.07 and 0.18 for all size fractions up to $1 \mu \mathrm{m}$, with values up to 0.48 for largest size fractions.

In 44 Seattle (Washington State, USA) residences, Allen et al. (2003) observed clear differences in the PM infiltration between the heating [mean \pm standard deviation (SD) $\left.\mathrm{F}_{\text {inf }} 0.53 \pm 0.16\right]$ and non-heating $(0.79 \pm 0.18)$ season. One of the largest population-based U.S. studies is the RIOPA study, which extensively analysed infiltration factors. Measurements of 48-h indoor, outdoor and personal $\mathrm{PM}_{2.5}$ concentrations were made in 374 non-smoking homes in Houston (TX), Los Angeles County (CA), and Elizabeth (NJ). Study-wide average infiltration factors were $0.51,0.78$, and 0.04 for $\mathrm{PM}_{2.5}$ associated with primary combustion, secondary formation (excluding nitrate), and mechanical generation, respectively, indicating particle size differences in the infiltration rate, as inferred from the source determined from the chemical composition (Meng et al. 2007). In their follow-up analysis of exposure determinants, the researchers found a clear non-linear dependence between the infiltration factor and outdoor temperature; $\mathrm{F}_{\text {inf }}$ decreased with both increasing and decreasing temperatures and was associated with air conditioning and heating, respectively, being the highest around $+20^{\circ} \mathrm{C}$ (Meng et al. 2009).
In addition to the above-mentioned U.S. studies, a number of datasets have been collected in Europe spanning the various climatological zones from Nordic to Mediterranean countries. In this study reported here, we first reviewed the literature to identify such studies and then contacted specific research groups to collect the original data in order to create a combined database of the observations and to analyse the geographical and seasonal infiltration factor patterns in Europe. The specific objectives of our study were (1) to identify and describe the most important European studies that have collected populationbased residential infiltration and ventilation rate data and to analyse the (2) geographical and (3) seasonal patterns in the infiltration factors in order to (4) improve the interpretation and understanding the epidemiology-observed relationships between PM air pollution, seasons and health.

\section{Material and methods}

We have attempted to identify all major indoor-outdoor PM measurement campaigns in Europe that would have at least limited seasonal coverage in one or more cities and in which infiltration factors were analysed for $\mathrm{PM}_{2.5}$ and, optionally, $\mathrm{PM}_{10}$. Data from six such studies became available (Table 1; see key references listed below in the summary of each study) and were pooled for the analysis of seasonal variability in the PM infiltration factors in different climatological regions of Europe. Data from Northern Europe were obtained on Gothenburg and Stockholm (Sweden) and Helsinki (Finland); Central Europe is represented by data on Amsterdam (Netherlands), Basle (Switzerland), Birmingham (UK) and Prague (Czech Republic); data on Southern Europe are available on Athens (Greece), Florence and Rome (Italy) (Fig. 1). Data for Athens and Helsinki were available from two different studies (EXPOLIS and RUPIOH), which enabled a comparison between two alternative methods used for determining infiltration factors at the building stock level. In Gothenburg and Stockholm two different elemental markers (sulphur and lead) were used in parallel, which also allowed for a direct comparison.

The data collection periods of the studies included in our meta-analysis varied from 2 to 18 months (Fig. 2). None of the studies was designed for the analysis of seasonal variability of PM levels or infiltration factors, but all of them included data from at least two seasons, defined as March-April-May (spring), June-July-August (summer), September-October-November (autumn) and DecemberJanuary-February (winter). At the European level, the number of residential data points per season varied from 74 (summer) to 112 (spring), while in individual regions, the number of data points by season ranged from 19 to 63 (spring, Southern vs. Northern Europe, respectively), 
Table 1 Studies, cities and data collection periods included in the analysis reported here and a comparison of the published central estimates of $\mathrm{PM}_{2.5}$ and $\mathrm{PM}_{10}$ infiltration factors in each study

\begin{tabular}{|c|c|c|c|c|c|c|c|}
\hline \multirow[t]{2}{*}{ Study } & \multirow[t]{2}{*}{ City } & \multirow{2}{*}{$\begin{array}{l}\text { Residences }^{\mathrm{a}} \\
\text { (sample pairs) }\end{array}$} & \multirow[t]{2}{*}{ Timeframe } & \multirow{2}{*}{$\begin{array}{l}\text { Duration per sample } \\
\text { (per location) }\end{array}$} & \multicolumn{3}{|c|}{ Overall Infiltration factor $\left(\mathrm{F}_{\mathrm{inf}}\right)$} \\
\hline & & & & & $\mathrm{PM}_{2.5}$ & $\mathrm{PM}_{10}$ & $\mathrm{PM}_{10} / \mathrm{PM}_{2.5}$ \\
\hline & & & & & Mean & Mean & \\
\hline \multirow[t]{4}{*}{ EXPOLIS } & Athens & $28(28)$ & 16.2.1997-18.3.1998 & 2 days ( 2 days) & 0.70 & $\mathrm{n} / \mathrm{a}$ & \\
\hline & Basel & $30(30)$ & 3.2.1997-23.1.1998 & 2 days ( 2 days $)$ & 0.63 & $\mathrm{n} / \mathrm{a}$ & \\
\hline & Helsinki & $84(84)$ & 28.10.1996-8.12.1997 & 2 days ( 2 days) & 0.59 & $\mathrm{n} / \mathrm{a}$ & \\
\hline & Prague & $16(16)$ & $3.6 .1997-4.6 .1998$ & 2 days ( 2 days) & 0.61 & $\mathrm{n} / \mathrm{a}$ & \\
\hline \multirow[t]{2}{*}{ HEARTS } & Florence & $38(38)$ & $30.9 .2004-22.12 .2004$ & 2 days ( 2 days) & 0.53 & $\mathrm{n} / \mathrm{a}$ & \\
\hline & & & & & Slope & Slope & \\
\hline \multirow[t]{2}{*}{ ISS } & Rome & $1^{\mathrm{b}}(116)$ & 21.4.1999-20.2.2000 & 1 day $(4 \times 1$ month $)$ & 0.62 & 0.47 & $76 \%$ \\
\hline & & & & & Median & Median & \\
\hline \multirow[t]{4}{*}{ RUPIOH } & Amsterdam & $50(321)$ & 19.10.2002-28.2.2004 & 1 day (1 week) & 0.39 & 0.35 & $89 \%$ \\
\hline & Athens & $35(213)$ & $26.10 .2002-21.3 .2004$ & 1 day (1 week) & 0.46 & 0.38 & $82 \%$ \\
\hline & Birmingham & $30(171)$ & 28.11.2002-7.3.2004 & 1 day (1 week) & 0.37 & 0.26 & $70 \%$ \\
\hline & Helsinki & $37(237)$ & $31.10 .2002-19.2 .2004$ & 1 day (1 week) & 0.48 & 0.44 & $92 \%$ \\
\hline \multirow[t]{2}{*}{ Sweden $^{\mathrm{c}}$} & Gothenburg & $29(29)$ & $2.4 .2002-30.10 .2003$ & 1 day (1 day) & 0.69 & $\mathrm{n} / \mathrm{a}$ & \\
\hline & Stockholm & $20(28)$ & $1.12 .2003-1.7 .2004$ & 1 day (1 day) & 0.70 & $\mathrm{n} / \mathrm{a}$ & \\
\hline
\end{tabular}

$\mathrm{PM}_{2.5}$ Particulate matter containing both fine $(<2.5 \mu \mathrm{m})$ and ultrafine particles $(<0.1 \mu \mathrm{m}) ; \mathrm{PM}_{10} \mathrm{PM}$ containing both coarse $(10-2.5 \mu \mathrm{m})$ and fine particles; $\mathrm{n} / \mathrm{a}$, data not available

${ }^{a}$ Number of residences included in the $\mathrm{F}_{\text {inf }}$ model; sample pair = concurrent indoor and outdoor measurement

${ }^{\mathrm{b}}$ In Rome, the measurements were conducted at an office of the Institute for approximately 1 month per season

${ }^{\mathrm{c}}$ Two separate studies conducted by some of the same authors

Fig. 1 Geographical coverage of the studies (main $\mathrm{F}_{\text {inf }}$ estimation method in parenthesis) and the participating cities (the symbols for the cities are also used in graphs on the results)

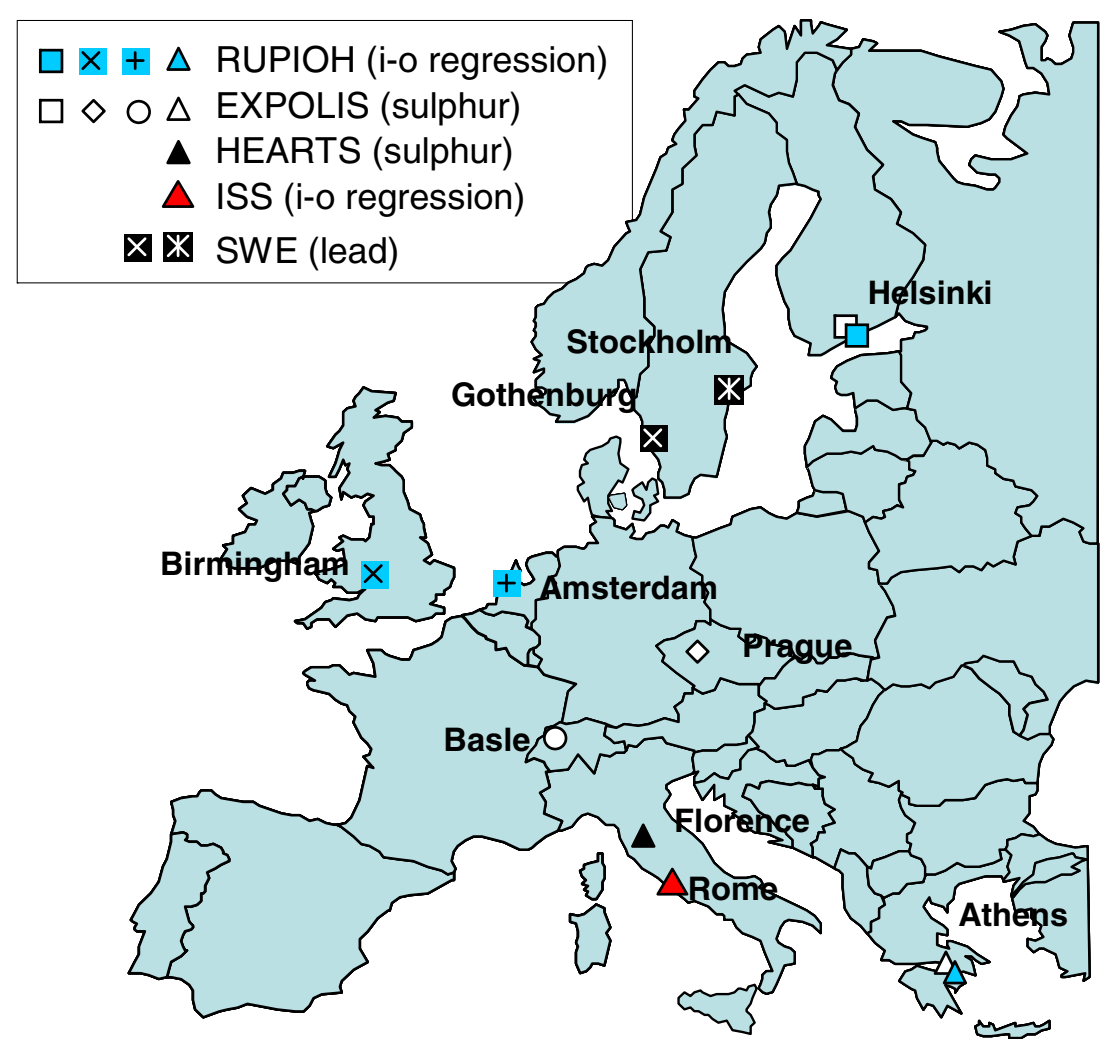


Fig. 2 Comparison of the seasonal coverage of the studies and the participating cities. The longest study (Gothenburg) lasted over 1 year and covered two summers; the shortest study (Florence) lasted only 2 months. All studies spanned at least two seasons, with a season defined as 3 consecutive months starting from 1 December

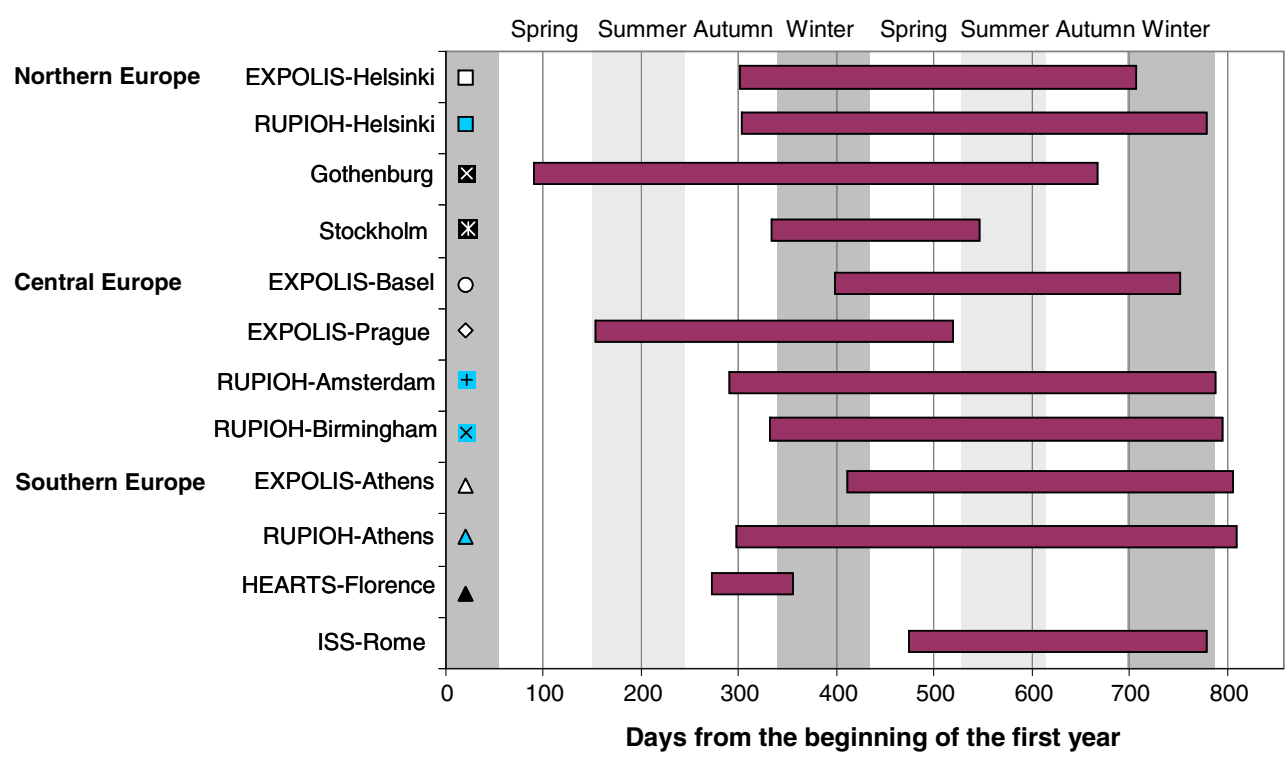

except for the summer season in Southern Europe, where only six data points were collected for residential areas. However, an additional 29 indoor and outdoor summer measurements were available from the ISS study in Rome (Table 2).

Overview of $\mathrm{F}_{\text {inf }}$ determination methods

All applied methods are based on simultaneous measurements of outdoor and indoor PM levels. In the EXPOLIS and HEARTS (Florence) studies, elemental sulphur was used as a marker of PM of ambient origin. The infiltration factor of $\mathrm{PM}_{2.5}$ was calculated by adjusting the sulphur infiltration factor by the ratio of the indoor/outdoor $\mathrm{PM}_{2.5}$ and corresponding sulphur regression slopes to account for the fact that sulphur is mostly present in the accumulation mode particles in sizes ranging typically from 200 to $800 \mathrm{~nm}$, which have higher penetration efficiencies and slower deposition rates than 1 - to $2.5-\mu \mathrm{m}$ particles (Hänninen et al. 2004a). In the RUPIOH and ISS studies,

Table 2 Statistical summary of the observed $\mathrm{PM}_{2.5}$ infiltration factors in the participating cities, the three regions and all data combined, by season and all seasons together, respectively

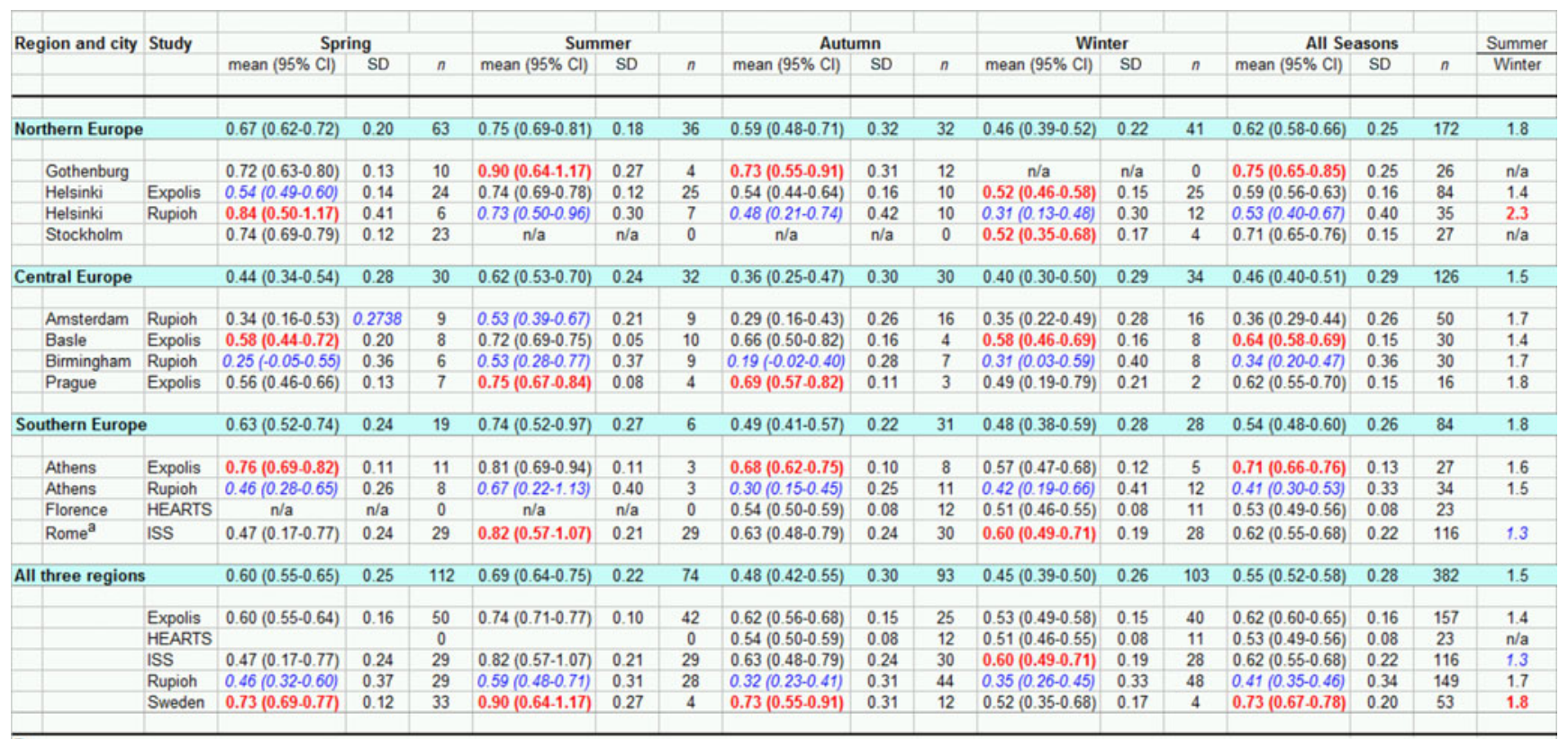

a Mean and standard error for Rome estimated using univariate regression from data measured at a single location; sd is presented for the Vo ratio. These values are not included in the Regional and European summaries.

$\mathrm{n} / \mathrm{a}=\mathrm{no}$ data available for the corresponding season.

highest value for each season in each region is shown in bold (red) and the lowest value in italics (blue) 
the infiltration of outdoor particles was estimated by regression analysis of simultaneously observed indoor and outdoor levels at each location. In the regression model, the slope can interpreted as the mean infiltration factor across the days and measurements included, and the intercept as the corresponding mean level of indoorgenerated particles. In Stockholm and Gothenburg, both sulphur and lead were available and used as elemental markers for ambient originating PM, but due to the larger fraction of samples below the limit of detection for sulphur, in our analysis we use slightly higher infiltration factors that were estimated using lead. These infiltration factors were not corrected for the potential difference between lead particles and $\mathrm{PM}_{2.5}$. The following paragraphs provide a concise summary of the basic design of the studies and sampling methods applied; for more details, the reader is directed to the original publication.

EXPOLIS study Representative random samples were drawn from the working age population in seven European cities in the EXPOLIS study (Athens, Basle, Grenoble, Helsinki, Milan, Oxford, Prague; Jantunen et al. 1998; Rotko et al. 2000). Residential indoor and outdoor measurements were conducted for 2 days at the homes of 50-200 subjects per city or metropolitan area. The study included measurements of indoor and outdoor $\mathrm{PM}_{2.5}$ (with 37 elements and black smoke) (Hänninen et al. 2004b). Infiltration analysis was successfully conducted for four cities (Athens, Basle, Helsinki and Prague; Hänninen et al. 2004a). The data were collected over approximately a 1-year period in each of the cities, covering more or less all seasons. A larger dataset was collected in Helsinki than in the other cities. Energydispersive X-ray fluorescence (EDXRF) spectrometry was used to analyse the elemental composition of the filter samples at the University of Basle (Mathys et al. 2001).

\section{HEARTS study The aim of the EU FP5 HEARTS project was} to develop and test integrated health impact assessment methods and to assess the changes in exposure patterns and the related health effects arising from various urban transport policies. Indoor and outdoor $\mathrm{PM}_{2.5}$ levels were measured in the residences of 38 volunteers in Florence as part of a case study between September 30 and December 222004 using the same standard operating procedures and sampling equipment as in the EXPOLIS study. (Fondelli et al. 2006, Fondelli et al., submitted; Mallone et al., submitted; WHO 2006).

RUPIOH study The RUPIOH study was conducted in Amsterdam, Athens, Birmingham and Helsinki (Hoek et al. 2008) and particle mass $\left(\mathrm{PM}_{10}\right.$ and $\left.\mathrm{PM}_{2.5}\right)$ and number concentrations (PNC), soot and sulfate concentrations were measured outside and inside the homes of 35 patients with asthma or chronic obstructive pulmonary disease (COPD) in each city. Daily indoor and outdoor measurements were collected for approximately 1 week, and indoor-outdoor regression was used to estimate the infiltration factor for $\mathrm{PM}_{2.5}$ and $\mathrm{PM}_{10}$ at each residence.

ISS study The ISS study in Rome measured indoor and outdoor of $\mathrm{PM}_{2.5}$ and $\mathrm{PM}_{10}$ simultaneously at two office rooms of the ISS Institute offices facing the main road and located downtown Rome (Cattani et al. 2003). The building (built in the 1950s) had a natural ventilation system with a local air conditioning system operated during working hours (0900-1700 hours) in the summer. The windows were normally kept closed, and no smokers were in the offices. A dichotomous sampler (Graseby-Andersen SA 241) working at $16.71 \mathrm{~min}^{-1}$ of flow rate and equipped with PTFE filters was used for coarse and fine outdoor measurements. A MEM sampler (SKC model 400 Micro-Environmental Monitor) working at $101 \mathrm{~min}^{-1}$ of flow rate and equipped with PTFE filters was used for indoor measurements. Filters were pre-conditioned for $24 \mathrm{~h}$ in a thermal-controlled glove box and then weighed before and after the exposure.

Gothenburg study This study took place in Gothenburg, Sweden, during two spring periods and two autumn periods in 2002 and 2003 (April 2-June 7 and September 26-November 6, 2002, and March 27-June 12 and October 7-30, 2003; Molnár et al. 2006). Personal, indoor and residential outdoor measurements of $\mathrm{PM}_{2.5}$ and $\mathrm{PM}_{1}$ in the homes of the subjects as well as $\mathrm{PM}_{2.5}$ at a stationary outdoor urban background station were made. The study included 30 subjects, eight men and 22 women, with a total of three smokers included among the participants. Identical sets of equipment were used for personal exposure and indoor and residential outdoor sampling, namely, a GK2.05 (KTL) cyclone with 37-mm Teflon filters (Pall Teflo model R2PJ037) for $\mathrm{PM}_{2.5}$ sampling connected to BGI $400 \mathrm{~S}$ personal sampling pumps with flow rates of $41 \mathrm{~min}^{-1}$. All filters were weighed before and after exposure using a CAHN C-30 microbalance placed in a temperature- and humidity-controlled room. An EDXRF spectrometer was used to analyse the elemental composition of all filter samples. The penetration indoors from outdoors was calculated as a ratio for both $\mathrm{S}$ and $\mathrm{Pb}$. The median penetration was 0.72 for $\mathrm{S}$ and 0.69 for $\mathrm{Pb}$, with $95 \%$ Confidence intervals $(\mathrm{CI})$ of $0.5-1$ for both.

Stockholm study This study was conducted in Stockholm, Sweden, between 1 December 2003 and 1 July 2004 and was divided into nine 2-week periods (Molnár et al. 2007). A total of 20 homes were selected for the study, and each home was measured twice. At each home, the samplers were turned on for 15 min every $2 \mathrm{~h}$ both day and night for the whole 14-day period. The homes were selected to 
represent different local conditions, such as traffic intensity and population density, and covered the same areas as those covered in the Traffic-Related Air Pollution on Childhood Asthma (TRAPCA) study. PM $_{2.5}$ was sampled on Andersen 37-mm 2- $\mu \mathrm{m}$ pore size Teflon filters (Anderson Samplers Atlanta, GA) with Harvard impactors. An EDXRF spectrometer was used to analyse the elemental composition of all filter samples. The median infiltration ratios calculated for $\mathrm{S}$ and $\mathrm{Pb}$ were 0.61 and 0.70 , respectively.

The datasets from the above studies were combined, identifying each infiltration factor by the calendar date, and the datasets were overlaid in three groups, one for each of Northern, Central and Southern Europe, using the Julian day; i.e. data from different cities and different years were overlaid using the number of days from 1 January as the index. Monthly and bimonthly temporal resolutions were used in the statistical analysis; due to the relatively limited number of data points, the main results presented are based on a bimonthly approach. In addition to the seasonal mean infiltration factors and the annual bimonthly profiles, corresponding $95 \%$ CIs are presented to characterize the uncertainties and \pm one standard deviations (SD) are shown for quantifying the population variability. The main focus of the work was $\mathrm{PM}_{2.5}$ infiltration that was covered by all of the identified studies. However, a substantial number of European studies on PM epidemiology have been, and still are focusing on $\mathrm{PM}_{10}$. Corresponding data were therefore available from two studies (RUPIOH and ISS) as well as $\mathrm{PM}_{1}$ data from the Swedish study conducted in Gothenburg. The differences in the infiltration factors of these PM size fractions are also discussed. Several of the studies provided additional data on air exchange rates and ambient meteorological conditions (especially temperature) that are known determinants of PM infiltration. Selected results are shown. but a systematic analysis of these factors across all the studies was not possible.

\section{Results}

Estimated annual residential mean $\mathrm{PM}_{2.5}$ infiltration rates in Northern, Central and Southern Europe were 0.62, 0.46, and 0.54 , respectively, with the overall average being 0.55 and the regional averages spanning by approximately 0.16 (25-33\% depending on the selection of the reference point) (Table 2). $\mathrm{PM}_{10}$ infiltration factors were available from two studies, and in relationship to $\mathrm{PM}_{2.5}$ they ranged from 70 to $92 \%$ (summary in Table 1). $\mathrm{PM}_{1}$ measurements were conducted in the Swedish studies in Gothenburg, where the observed $\mathrm{PM}_{1}$ infiltration factor was 0.89 (78\% of the corresponding $\mathrm{PM}_{2.5}$ infiltration).
Seasonal profiles of all three European regions exhibit a better insulation of indoor spaces from the outdoor air during the winter season and show the highest infiltration factors during the summer (Fig. 3). The seasonal profiles show considerable overlapping between the cities and the regions, demonstrating that the short-term variability within the regions is larger than the actual differences between the regions.

Potential complications due to differences in the study designs and methods can be avoided by looking at multicenter studies based on harmonized quality-controlled methods across the included cities. In EXPOLIS, the largest $\mathrm{PM}_{2.5}$ infiltration factor was observed in Athens (0.71), followed by Basel and Prague (0.64 and 0.62, respectively), with Helsinki remaining the lowest at 0.59. In all EXPOLIS cities, the observed seasonal pattern consisted of the highest $\mathrm{PM}_{2.5}$ infiltration levels during the summer and the lowest during the winter, followed by spring (Table 2). In the RUPIOH study, the observed average infiltration factors were lower than those in EXPOLIS in the two cities with data from both of the studies (Helsinki and Athens). RUPIOH also showed the lowest average infiltration factors over all cities covered by each study. Nevertheless, the seasonal profiles were consistent among all studies with the minor exception of Helsinki in RUPIOH, where the spring infiltration factor slightly exceeded the summer value $(0.84$ and 0.73 , respectively; Table 2).

Single short-term measurements capture both the variability of infiltration between buildings and the variability within the same location, and thus the observed variance in each city and study is a combination of intra- and interbuilding variability. The smallest overall variability of the infiltration factor was observed in Florence, where also the shortest period of observations was included $\left(\mathrm{F}_{\text {inf }} \mathrm{SD}=0.08\right)$, and the largest was observed in RUPIOH-Helsinki (0.40). Overall, the largest variability was observed in RUPIOH in all three regions, likely due to the indoor-outdoor regression method. In comparison with the between-region differences, the within-city variability dominates. The within-region variability is quite comparable across the three regions, with the SD ranging from 0.25 to 0.29 (Northern and Central Europe, respectively) (TableI 2).

The ISS study was based on a different design: the $\mathrm{PM}_{2.5}$ and $\mathrm{PM}_{10}$ measurements were conducted at a single research institute location. The indoor and outdoor levels were collected for a 1-month period during each season, and the seasonal mean infiltration factors were estimated for both PM fractions using indoor-outdoor regression (Fig. 4). The regression slopes exhibited a seasonal variability similar to that observed in the other studies, except that the highest infiltration during summer was contrasted with the lowest value in the spring; this result may possibly reflect the meteorological conditions during that particular 


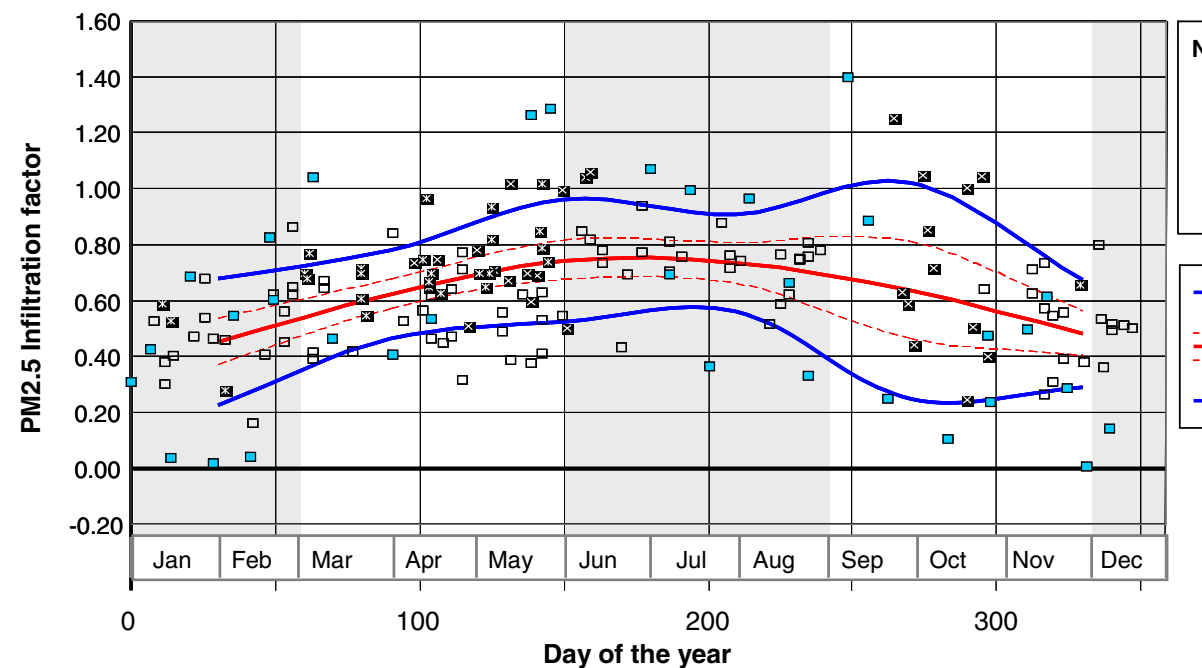
Northern Europe
RUPIOH-Helsinki
口 EXPOLIS-Helsinki
x Gothenburg
* Stockholm

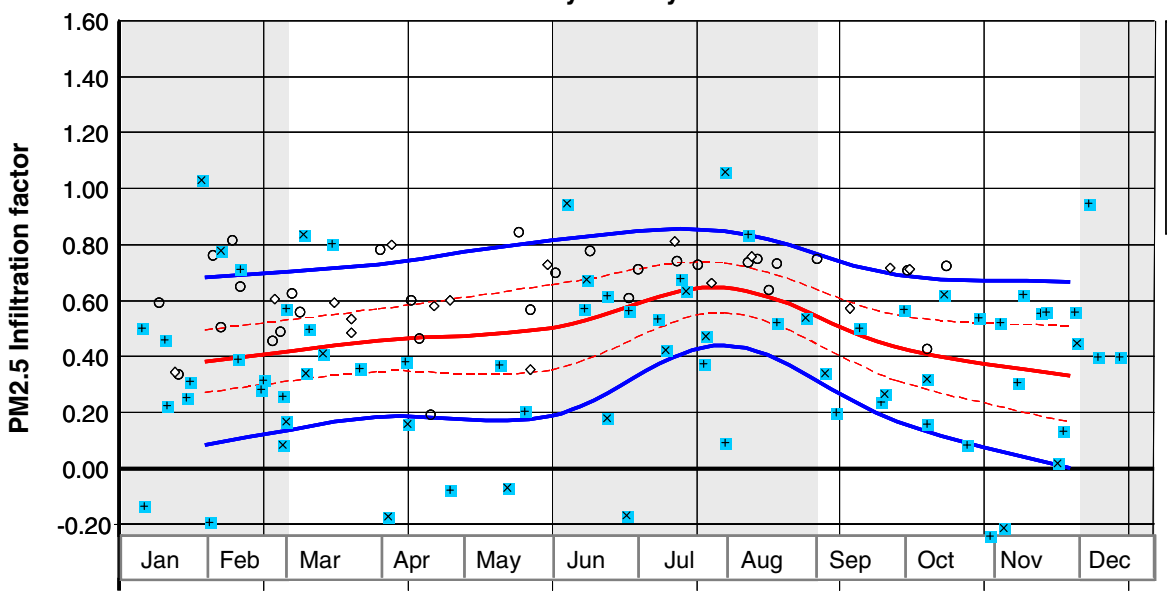

\section{Central Europe \\ + RUPIOH-Amsterdam \\ $x$ RUPIOH-Birmingham \\ ○ EXPOLIS-Basle \\ $\diamond$ EXPOLIS-Prague}

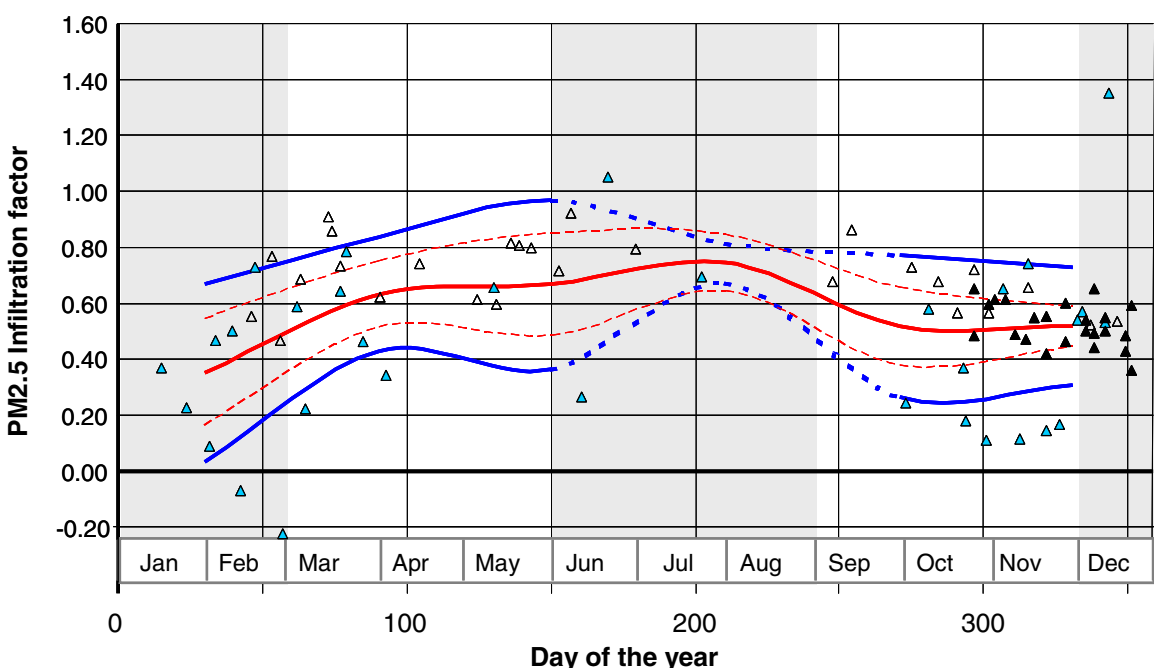

Southern Europe

$\triangle$ RUPIOH-Athens

$\triangle$ EXPOLIS-Athens

\ HEARTS-Florence

Fig. 3 Seasonal variation in $\mathrm{PM}_{2.5}$ infiltration factors as observed in the respective studies. The thick central line represents the bimonthly averages accompanied with $95 \%$ dashed confidence intervals. The variability between buildings and sampling days is characterized by intervals bounded by the outer thick lines representing the mean \pm standard deviation (SD) (in Southern Europe, due to the limited data in July August, the variability estimate is not representative and the corresponding parts of the lines are shown as a dotted line; see discussion of values below 0 and above 1 and data filtering criteria in the text) 
Fig. 4 Seasonal regression slopes for Rome (ISS Study; extrapolation outside the seasonal data range shown by dotted lines). The constant terms approximate the mean indoor source concentrations varying from $0.37 \mu \mathrm{g} \mathrm{m}^{-3}$ in the summer to $8.5 \mu \mathrm{g} \mathrm{m}^{-3}$ in the spring. These estimates are relatively more sensitive to outliers than the slopes estimating infiltration factors

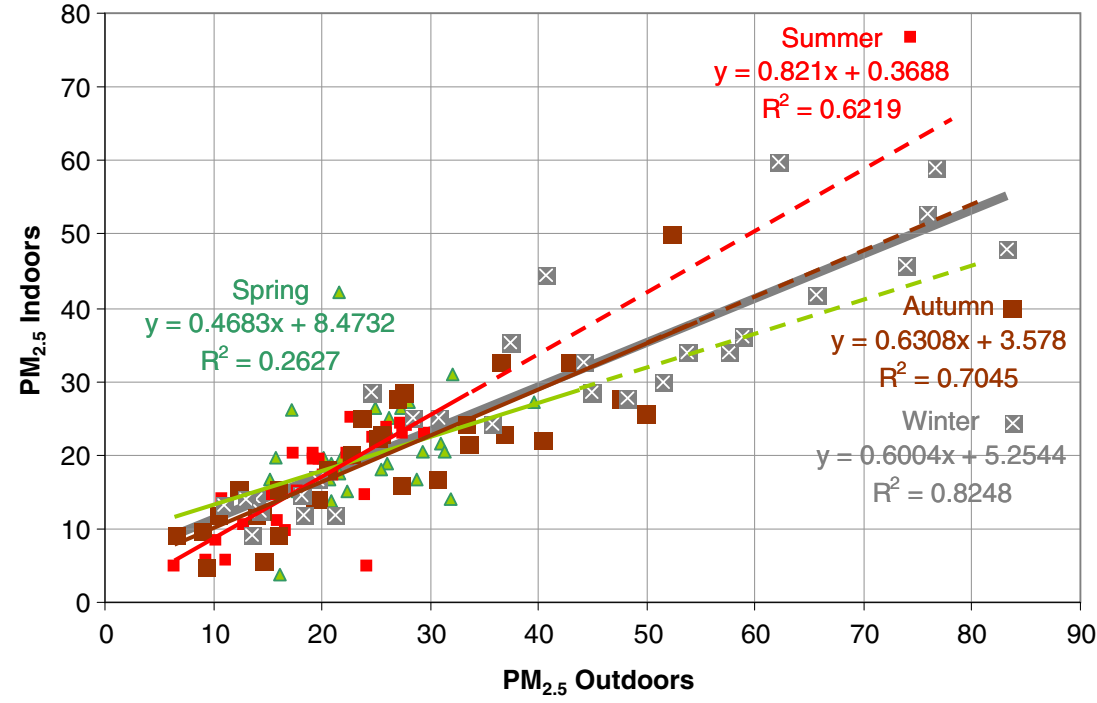

year, but the spring period was also associated with the smallest range, which may have affected regression. The coefficient of determination $\left(r^{2}\right)$ was only $26 \%$ for the spring, while ranging from 62 to $82 \%$ during the other seasons. For the other seasons, the $\mathrm{PM}_{2.5}$ infiltration factors were comparable with the EXPOLIS data from Athens and the HEARTS data from Florence (only autumn/winter partly covered).

Ventilation rates were estimated from the EXPOLIS, HEARTS and RUPIOH data (Table 3). Air exchange rates (AER) exhibit a similar seasonal pattern as infiltration factors, and this pattern is known to be the main cause of the annual variability in PM infiltration (Fig. 5). In the EXPOLIS data for Athens, the mean AER varied from $0.6 \mathrm{~h}^{-1}$ during December-January to $2.5 \mathrm{~h}^{-1}$ in summer (very limited number of measurements, $n=3$ ). More representative sampling was available for the spring with mean AER of $1.5 \mathrm{~h}^{-1}$. In Northern Europe, the ventilation rate ranged from $0.4 \mathrm{~h}^{-1}$ in December to $1.4 \mathrm{~h}^{-1}$ in August.
Ventilation rates observed in the RUPIOH study were lower than those in EXPOLIS for all seasons, a finding that is consistent with the corresponding observed infiltration factors (Table 3). The EXPOLIS study was based on working age (25-55 years): subjects randomly drawn from the general population, while the RUPIOH subjects were 35 years or older patients with diagnosed asthma or chronic obstructive pulmonary disease and not working for more than $16 \mathrm{~h}$ in a week outside their homes. Participants in the RUPIOH study were thus more likely to protect themselves from ambient pollution when possible.

The HEARTS measurements conducted in Florence (Fig. 6) demonstrate an association between ambient temperature and the $\mathrm{PM}_{2.5}$ infiltration factor that was also observed in the EXPOLIS cities with temperature data available (data not shown). In Florence, the residential $\mathrm{PM}_{2.5}$ infiltration factors ranged from 0.36 to 0.65 , and $16 \%$ of the variance was explained by the ambient temperature (Fig. 6).

Table 3 Statistical summary of the observed ventilation rates (AER, $\mathrm{h}^{-1}$ )in the three studies from which these data are available, by season and all seasons together

\begin{tabular}{|c|c|c|c|c|c|c|c|c|c|c|c|c|c|c|c|c|c|}
\hline City & Study & $\begin{array}{l}\text { Spring } \\
\text { mean }(95 \% \mathrm{Cl})\end{array}$ & SD & $n$ & $\begin{array}{l}\text { Summer } \\
\text { mean }(95 \% \mathrm{Cl})\end{array}$ & SD & $n$ & $\begin{array}{l}\text { Autumn } \\
\text { mean }(95 \% \mathrm{Cl})\end{array}$ & SD & $n$ & $\begin{array}{l}\text { Winter } \\
\text { mean }(95 \% \mathrm{Cl})\end{array}$ & SD & $n$ & $\begin{array}{l}\text { Whole year } \\
\text { mean }(95 \% \mathrm{Cl})\end{array}$ & SD & $n$ & $\frac{\text { Summer }}{\text { Winter }}$ \\
\hline Athens & Expolis & $1.50(0.87-2.13)$ & 1.0 & 11 & $2.52(-0.01-5.06)$ & 2.2 & 3 & $1.00(0.55-1.45)$ & 0.6 & 8 & $0.61(0.25-0.96)$ & 0.4 & 5 & $1.30(0.87-1.73)$ & 1.1 & 27 & 4.2 \\
\hline Basle & Expolis & $0.76(0.31-1.21)$ & 0.6 & 8 & $0.99(0.85-1.13)$ & 0.2 & 10 & $0.85(0.47-1.23)$ & 0.4 & 4 & $0.68(0.32-1.05)$ & 0.5 & 8 & $0.83(0.66-0.99)$ & 0.5 & 30 & 1.5 \\
\hline Helsinki & Expolis & $0.57(0.39-0.74)$ & 0.4 & 24 & $1.43(0.95-1.91)$ & 1.2 & 25 & $0.55(0.35-0.76)$ & 0.3 & 10 & $0.53(0.33-0.73)$ & 0.5 & 25 & $0.81(0.63-1.00)$ & 0.8 & 84 & 2.8 \\
\hline Prague & Expolis & $0.60(0.28-0.92)$ & 0.4 & 7 & $1.16(0.79-1.52)$ & 0.4 & 4 & $0.81(0.52-1.10)$ & 0.3 & 3 & $0.40(0.01-0.79)$ & 0.3 & 2 & $0.75(0.54-0.97)$ & 0.4 & 16 & 2.8 \\
\hline All & Expolis & $0.81(0.60-1.01)$ & 0.73 & 50 & $1.38(1.03-1.72)$ & 1.11 & 42 & $0.77(0.59-0.96)$ & 0.47 & 25 & $0.56(0.41-0.72)$ & 0.48 & 40 & $0.89(0.76-1.02)$ & 0.82 & 157 & 2.6 \\
\hline Amsterdam & Rupioh & $0.95(0.46-1.45)$ & 0.7 & 9 & $1.42(0.53-2.30)$ & 1.3 & 9 & $0.59(0.36-0.82)$ & 0.5 & 16 & $0.49(0.40-0.58)$ & 0.2 & 16 & $0.77(0.56-0.99)$ & 0.8 & 50 & 3.5 \\
\hline Athens & Rupioh & $0.14(0.03-0.24)$ & 0.2 & 9 & $2.03(-0.67-4.74)$ & 2.3 & 3 & $0.15(0.03-0.26)$ & 0.2 & 11 & $0.25(0.15-0.35)$ & 0.2 & 12 & $0.34(0.07-0.61)$ & 0.8 & 35 & 10.0 \\
\hline Birmingham & Rupioh & $0.41(0.17-0.65)$ & 0.3 & 6 & $0.39(0.13-0.65)$ & 0.4 & 9 & $0.22(0.13-0.31)$ & 0.1 & 7 & $0.21(0.08-0.35)$ & 0.2 & 8 & $0.31(0.21-0.41)$ & 0.3 & 30 & 1.5 \\
\hline Helsinki & Rupioh & $0.77(0.30-1.23)$ & 0.6 & 6 & $1.10(0.84-1.35)$ & 0.3 & 7 & $0.53(0.21-0.86)$ & 0.5 & 11 & $0.38(0.28-0.48)$ & 0.2 & 13 & $0.62(0.47-0.78)$ & 0.5 & 37 & 3.7 \\
\hline All & Rupioh & $0.56(0.35-0.78)$ & 0.59 & 30 & $1.07(0.64-1.50)$ & 1.14 & 28 & $0.41(0.28-0.54)$ & 0.43 & 45 & $0.36(0.30-0.42)$ & 0.21 & 49 & $0.55(0.44-0.65)$ & 0.66 & 152 & 3.3 \\
\hline Florence & Hearts & $\mathrm{n} / \mathrm{a}$ & & 0 & $\mathrm{n} / \mathrm{a}$ & & 0 & $0.36(0.31-0.42)$ & 0.1 & 12 & $0.32(0.26-0.38)$ & 0.1 & 11 & $0.34(0.30-0.38)$ & 0.1 & 23 & $\mathrm{n} / \mathrm{a}$ \\
\hline
\end{tabular}

highest value for each season is shown in bold (red) and lowest value in italics (blue) 

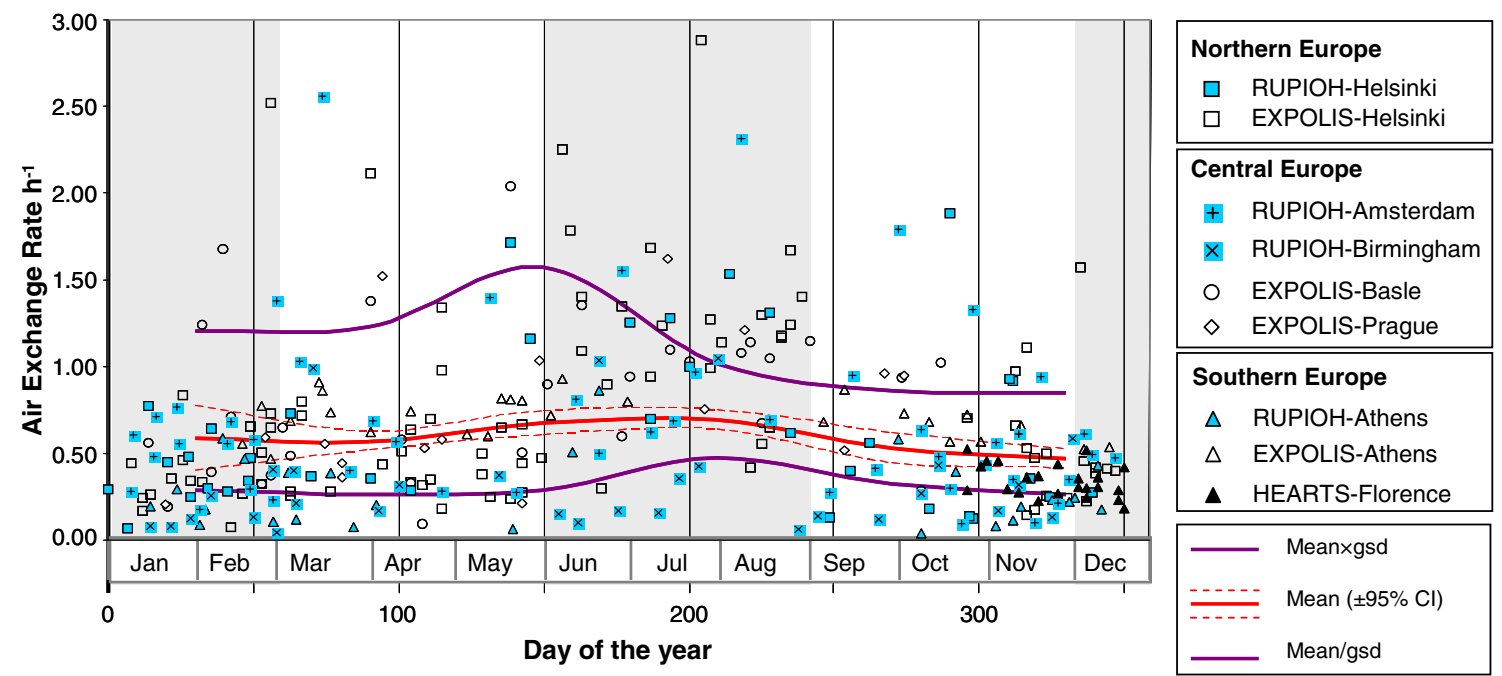

Fig. 5 Seasonal variation in air exchange rates in the EXPOLIS and RUPIOH cities and Florence. (Three datapoints above $3 \mathrm{~h}^{-1}$, not visible on the selected scale)

\section{Discussion and uncertainties}

According to the results, the average $\mathrm{PM}_{2.5}$ infiltration can vary almost by a factor of two between the summer and the winter, and even when the $10-15 \%$ of time not spent indoors is accounted for, a similar variation would be expected in the outdoor $\mathrm{C}-\mathrm{R}$ ratios that would be observed in epidemiological studies due to modifications in seasonal exposure. The magnitude of the seasonal differences in the observed $\mathrm{C}-\mathrm{R}$ relationships in various studies has, indeed, been in the same range as this factor. The fact that different studies have observed opposite summer-winter relationships (e.g. Bell et al. 2008 vs. Samoli et al. 2005) indicates that a better understanding of the study design and the exposure modification by the season is required and that especially the differences in the seasonal use of air conditioning, open windows and heating systems need to be characterized and accounted for.

Hystad et al. (2009) investigated the indoor-outdoor relationship of PM concentrations in Seattle (WA; 46 residences; data collected in 1999-2003; Allen et al. 2003) and Victoria (CA; 38 residences; 2006) using portable nephelometers measuring light scattering and calculated $\mathrm{F}_{\text {inf }}$ values with a recursive mass balance model from hourly observations. These researchers observed lower $F_{\text {inf }}$ for the heating season (median approximately 0.5 ) compared to the non-heating (0.75) season, which is consistent with the current findings from European cities. Hystad et al. (2009) estimated that the prevalence of air conditioning units is 6\% in Seattle and 3\% in Victoria, i.e. very low, as in Europe.

Variability of the infiltration in the same buildings or effects of weather could not be analysed from the current
Fig. 6 Association of the $\mathrm{PM}_{2.5}$ infiltration factor and ambient temperature in Florence, Italy in the HEARTS study, where all the measurements were conducted in a 2-month period during the transition from autumn to winter

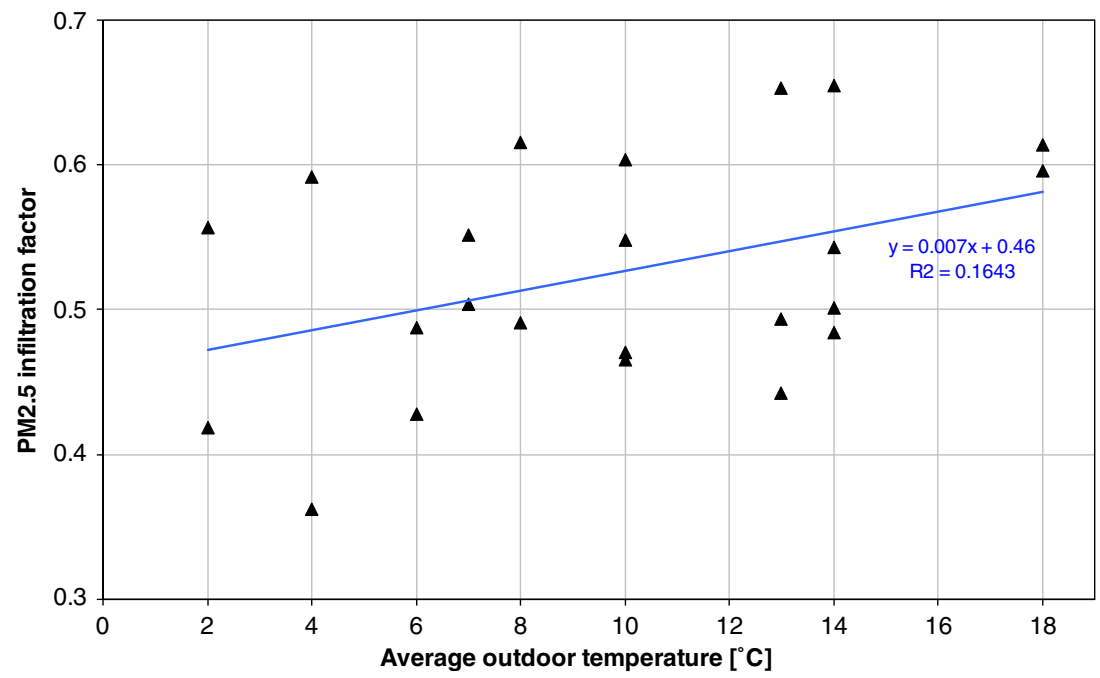


data. In EXPOLIS, HEARTS and the Gothenburg studies, measurement were conducted only once at each building, and in Rome (ISS study) and in the RUPIOH cities, the repeated concentration measurements were used in the infiltration factor analysis using regression over the timeseries; thus the time-series of the infiltration factors themselves did not become available.

The uncertainties in the current analysis can be divided into two main categories: (1) geographical and temporal representativity and (2) methodological issues. The number of cities included (10 in whole Europe; 3, 4 and 3 in Northern, Central and Southern Europe, respectively) is of course limited, and the spatial representativeness could be questioned. Specifically, Prague is the only city that to some extent can be considered to represent Eastern Europe, and South-Western Europe (France, Spain and Portugal) is not represented at all. However, the wide distributions in each city from the available regions indicate that the variability of infiltration within each city is larger than the differences between the cities. The cities spanning from North Europe to South Europe also should capture the main differences in building construction and ventilation technology that are influenced by the climate zones. Therefore, while limited, the spatial representativeness does not seem to be a major concern. Temporally, the studies included in our meta-analysis range from 2 months to 18 months in length; all seasons are not equally sampled (Fig. 2), but the regional numbers of samples available for each season are comparable, ranging from 28 to 63 (winter/Southern Europe, spring/Northern Europe), excluding spring and summer in Southern Europe with 19 and six samples only, respectively. Thus, in the temporal sense the main remaining uncertainty concerns the summer season in the Mediterranean region.

Clear differences can be seen in the included studies in terms of average infiltration factors. The two Swedish studies estimated the highest infiltration factors $(0.71$ in Stockholm and 0.75 in Gothenburg) even though they targeted Northern European building stocks. In comparison, the levels seem to be about $30 \%$ higher with the Helsinki data (0.59 in EXPOLIS and 0.53 in RUPIOH).

RUPIOH and EXPOLIS both included one Northern European, two Central European and one Southern European city and collected samples similarly over the whole calendar year. Nevertheless, the observed mean infiltration factors were 0.41 and 0.62 , respectively. The study populations and methods used to estimate the infiltration factors in these studies differed in all three cases, and it seems likely that at least part of the differences observed may be attributable to the study design and methods. Without parallel measurements and a more detailed quality control programme, it was and is difficult to judge the individual methods applied and, therefore, the current approach of presenting statistics from the pooled data was chosen. The combined dataset that emerged includes the methodological disparities, but it can be expected that the combination of different methods will to some extent average out the effects of the different methods. In addition, the observed seasonality patterns - the main focus of our study - are similar in both studies. The remaining problem is that the methods were not applied equally in the cities of the different regions and that part of the observed regional differences may be caused by the study designs and not by actual differences in the infiltration levels.

The largest year-around infiltration factor was unexpectedly observed for Northern Europe, where especially over the cold season buildings are well insulated and separated from outdoor air. The result is likely to be partly attributable to the differences in the methods of determining infiltration factors. For example, the data from Northern Europe combines one dataset from the RUPIOH study, which showed overall the lowest infiltration factors, and with those from the two Swedish studies with the highest study averages (Table 2), while Central Europe has two cities from RUPIOH (lower estimates) and two cities from EXPOLIS (non-extreme estimates). The data from Southern Europe combines two cities using the EXPOLIS methodology (Athens and HEARTS-Florence, with a relatively small sample size), one city from RUPIOH, and the ISS study, which regardless of the large daily sample size could not be combined with the data from the other cities in the calculation of the regional averages

RUPIOH and the ISS study in Rome provided valuable data on $\mathrm{PM}_{10}$. Its coarse fraction has a lower penetration and higher settling velocity indoors than the fine fraction $\left(\mathrm{PM}_{2.5}\right)$. Interestingly, both studies showed lower seasonal variability for the infiltration of $\mathrm{PM}_{10}$ particles than for $\mathrm{PM}_{2.5}$. The Rome data displayed the highest uncertainty for the spring season. The HEARTS study was limited to 2 months but, nevertheless, within this period displayed a consistent relationship with both temperature and the changing season.

Determination of city-wide population-based infiltration factor distributions remains challenging due to the required population sample size and campaign duration. Wind and rain apparently also affect the ventilation patterns and therefore infiltration, but our study did not consider these associations; a follow-up in this direction is suggested. In naturally ventilated buildings, the air exchange rate is driven by the temperature difference between indoor and outdoor air and wind pressure, and the main method for occupants to adjust the ventilation is by opening windows. Detailed measurements under controlled conditions could be used to develop a statistical model between these variables that are relatively easy to collect; such a model could significantly improve the exposure assessment and thus effect estimates in some epidemiological studies. 


\section{Conclusions}

Clear seasonal trends in the infiltration of ambient pollution indoors are created by the ventilation patterns that are dependent on the variation in meteorological conditions, including temperature. These observed trends affect the relationship between ambient concentrations and corresponding population exposures and are therefore important for the interpretation of epidemiological studies comparing the health impacts of PM in different seasons and for the analysis of interaction between temperature and air pollution in epidemiological studies.

The overall annual $\mathrm{PM}_{2.5}$ infiltration factor calculated as an average of all samples in the five residential studies analysed here was 0.55 (95\% CI 0.52-0.58). A clear seasonal trend with increased infiltration during the summer and lowest values for the winter could be observed in the overall data as well as in regional subsets for Southern, Central and Northern Europe. Differences between the regions were smaller, however, than the variability within each city and each region. The highest annual infiltration was observed in Northern Europe (0.62; 95\% CI 0.58-0.66) and the smallest in Central Europe $(0.46 ; 95 \%$ CI $0.40-0.51)$. The difference may be attributable to the differences in the study designs and methods applied in variable degree in each region.

The higher $\mathrm{C}-\mathrm{R}$ relationships observed in the reviewed epidemiological studies for the summer in Europe are potentially caused by the fact that the population exposures per a certain ambient level are actually higher in summer than in winter, and when presented as function of the ambient level, the apparent $\mathrm{C}-\mathrm{R}$ ratio is higher. Moreover, during the summer a potentially larger fraction of time is spent outdoors.

In epidemiological studies, additional variability in the exposure descriptor typically leads to a bias towards zero, which can also partly explain the lower $\mathrm{C}-\mathrm{R}$ findings for winter periods. However, it has been also suggested that the winter particles with a larger contribution from local fresh combustion could actually be more harmful. Moreover, the local combustion particles are typically in the ultrafine particle fraction, which has the smallest infiltration rates. Correct interpretation of the epidemiological findings requires a population-based quantitative understanding of infiltration and corresponding modification of population exposures.

Acknowledgements This work has been supported by EU Contracts FP7-ENV-2009-1-243406 (TRANSPHORM), EVK4-CT-2002-00097 (FUMAPEX) and N ENV4-CT96-0202 (EXPOLIS; DG12-DTEE), Academy of Finland Contracts 133792 (PM Sizex), 36586, 40835 and 42610 , and intramural funding by THL. RUPIOH was funded by the European Union Quality of Life and Management of Living Resources programme, contract QLRT-2001-00452. The Swedish work was supported by the Swedish National Air Pollution and Health Effects Programme (SNAP) and the Swedish Environment Protection Agency.

\section{References}

Allen R, Larson T, Sheppard L, Wallace L, Liu LJS (2003) Use of real-time light scattering data to estimate the contribution of infiltrated and indoor-generated particles to indoor air. Environ Sci Technol 37(16):3484-3492

Bell ML, Ebisu K, Peng RD, Walker J, Samet JM, Zeger SL, Dominici F (2008) Seasonal and regional short-term effects of fine particles on hospital admissions in 202 US Counties, 19992005. Am J Epidemiol 168(11):1301-1310. doi:10.1093/aje/ kwn252

Bennett DH, Koutrakis P (2006) Determining the infiltration of outdoor particles in the indoor environment using a dynamic model. J Aerosol Sci 37:766-785

Cattani G, Cusano MC, Inglessis M, Settimo G, Stacchini G, Ziemacki G, Marconi A (2003) Misure di materiale particellari PM10 e PM2.5 a Roma: confronti indoor/outdoor (In Italian). Ann Ist Super Sanità 39(3):357-364. Available at: http://www. iss.it/publ/anna/2003/3/393357.pdf. Accessed 2 Feb 2009

Dockery DW, Spengler JD (1981) Indoor-outdoor relationships of respirable sulfates and particles. Atmos Environ 15:335-343

Fondelli MC, Gasparrini A, Mallone S, Chellini E, Cenni I, Nava S, Grechi D, Yli-Tuomi T, Jantunen M (2006) The effect of traffic emission on personal PM2.5 exposure. Epidemiology 17(6):S58

Hänninen O, Jantunen M (2007) Response to findings on association between temperature and dose-response coefficient of inhalable particles (PM10). J Epidemiol Community Health 61(9):838

Hänninen OO, Lebret E, Ilacqua V, Katsouyanni K, Künzli N, Srám RJ, Jantunen MJ (2004a) Infiltration of ambient PM2.5 and levels of indoor generated non-ETS PM2.5 in residences of four European cities. Atmos Environ 38(37):6411-6423

Hänninen OO, Alm S, Katsouyanni K, Künzli N, Maroni M, Nieuwenhuijsen MJ, Saarela K, Srám RJ, Zmirou D, Jantunen MJ (2004b) The EXPOLIS Study: implications for exposure research and environmental policy in Europe. J Expo Anal Environ Epidemiol 14:440-456

Hoek G, Kos G, Harrison R, de Hartog J, Meliefste K, ten Brink H, Katsouyanni K, Karakatsani A, Lianou M, Kotronarou A, Kavouras I, Pekkanen J, Vallius M, Kulmala M, Puustinen A, Thomas S, Meddings C, Ayres J, van Wijnen J, Hameri K (2008) Indoor-outdoor relationships of particle number and mass in four European cities. Atmos Environ 42:156-169

Hollander AEM de, Melse JM, Lebret E, Kramers PGN (1999) An aggregate public health indicator to represent the impact of multiple environmental exposures. Epidemiology 10(5):606617

Hystad P, Setton E, Allen R, Keller P, Brauer M (2009) Modeling residential fine particulate matter infiltration for exposure assessment. J Expo Sci Environ Epidemiol 19(6):570-579

Janssen NAH, Schwarz J, Zanobetti A, Suh H (2002) Air conditioning and source-specific particles as modifiers of the effect of PM10 on hospital admissions for heart and lung disease. Environ Health Perspect 110:43-49

Jantunen MJ, Hänninen OO, Katsouyanni K, Knöppel H, Künzli N, Lebret E, Maroni M, Saarela K, Srám RJ, Zmirou D (1998) Air pollution exposure in European cities: the EXPOLIS-study. J Expo Anal Environ Epidemiol 8(4):495-518

Koistinen KJ, Hänninen OO, Rotko T, Edwards RD, Moschandreas D, Jantunen MJ (2001) Behavioral and environmental determinants of personal exposures to PM2.5 in EXPOLIS-Helsinki, Finland. Atmos Environ 35(14):2473-2481

Long CM, Suh HH, Catalano PJ, Koutrakis P (2001) Using timeand size-resolved particulate data to quantify indoor penetration and deposition behavior. Environ Sci Technol 35 (10):2089-2099 
Mathys P, Stern WB, Oglesby L, Braun-Fahrländer C, AckermannLiebrich U, Jantunen M, Künzli N (2001) Elemental analysis of airborne particulate matter by ED-XRF within the European EXPOLIS study. ICP Inf Newsl 27(3):29-34

Meng QY, Turpin BJ, Lee JH, Polidory A, Weisel CP, Morandi M, Colome S, Zhang J, Stock T (2007) How does infiltration behavior modify the composition of ambient PM2.5 in indoor spaces? An analysis of RIOPA data. Environ Sci Technol 41:7315-7321

Meng QY, Spector D, Colome S, Turpin B (2009) Determinants of indoor and personal exposure to PM2.5 of indoor and outdoor origin during the RIOPA study. Atmos Environ 43(36):57505758. doi: 10.1016/j.atmosenv.2009.07.066

Molnár P, Johannesson S, Boman J, Barregård L, Sällsten G (2006) Personal exposures and indoor, residential outdoor, and urban background levels of fine particle trace elements in the general population. J Environ Monit 8(5):543-551

Molnár P, Bellander T, Sällsten G, Boman J (2007) Indoor and outdoor concentrations of PM2.5 trace elements at homes, preschools and schools in Stockholm, Sweden. J Environ Monit 9(4):348-357

Nawrot TS, Torfs R, Fierens F, De Henauw S, Hoet PH, Van Kersschaever G, De Backer G, Nemery B (2007) Stronger associations between daily mortality and winter: evidence from a heavily polluted region in fine particulate air pollution in summer than in Western Europe. J Epidemiol Community Health 61:146149

Ren C, Williams GM, Tong S (2006) Does particulate matter modify cardiorespiratory diseases? Environ Health Perspect 114 (11):1690-1696

Rotko T, Oglesby L, Künzli N, Jantunen M (2000) Population sampling in European air pollution exposure study, EXPOLIS: comparisons between the cities and representativity of the samples. J Expo Anal Environ Epidemiol 10(4):355-364
Samoli E, Analitis A, Touloumi G, Schwartz J, Anderson HR, Sunyer J, Bisanti L, Zmirou D, Vonk JM, Pekkanen J, Goodman P, Paldy A, Schindler C, Katsouyanni K (2005) Estimating the exposureresponse relationships between particulate matter and mortality within the APHEA multicity project. Environ Health Perspect 113:88-95. doi:10.1289/ehp. 7387

Stafoggia M, Schwartz J, Forastiere F, Perucci CA, the SISTI Group (2008) Does temperature modify the association between air pollution and mortality? A multicity case-crossover analysis in Italy. Am J Epidemiol 167(12):1476-1485. doi:10.1093/aje/kwn074

Watkiss P, Pye S, Holland M (2005) CAFÉ CBA: baseline analysis 2000 to 2020. AEAT/ED51014/Baseline Scenarios Issue 5. AEA Technology Environment, Oxon. Available at: http://ec.europa. eu/environment/archives/air/cafe/activities/pdf/cba_baseline_ results2000_2020.pdf

Welty LJ, Zeger SL (2005) Are the acute effects of particulate matter on mortality in the national morbidity, mortality, and air pollution study the result of inadequate control for weather and season? A sensitivity analysis using flexible distributed lag models. Am J Epidemiol 162(1):80-88

WHO (2003) World health report 2002: reducing risks, promoting healthy life. WHO, Geneva

WHO (2006) Health effects and risks of transport systems: the HEARTS project. WHO, Copenhagen. Available at: http:// www.euro.who.int/document/e88772.pdf. Accessed 19 Nov 2008

Wilson WE, Brauer M (2006) Estimation of ambient and nonambient components of particulate matter exposure from a personal monitoring panel study. J Expo Sci Environ Epidemiol $16: 264-274$

Wilson WE, Mage DT, Grant LD (2000) Estimating separately personal exposure to am-bient and nonambient particulate matter for epidemiology and risk assessment: why and how. J Air Waste Manage Assoc 50(7):1167-1183 